\title{
Evaluation of endometrial thickness in postmenopausal women by using 3.0-T MRI
}

\begin{abstract}
Authors:
Junko Nakamura ${ }^{1}$

Takeharu Yoshikawa²

Eriko Maeda ${ }^{2}$

Hiroyuki Akai ${ }^{3}$

Hiroshi Ohtsu ${ }^{4}$

Naoto Hayashi ${ }^{2}$

Kuni Ohtomo ${ }^{1}$

Affiliations:

${ }^{1}$ Department of Radiology, Graduate School of

Medicine, The University of Tokyo, Japan

${ }^{2}$ Department of

Computational Diagnostic Radiology and Preventive

Medicine, The University of

Tokyo Hospital, Japan

${ }^{3}$ Department of Radiology, Research Hospital The

Institute of Medical Science,

The University of Tokyo, Japan

${ }^{4}$ Department of Clinical Trial Data Management, The University of Tokyo Hospital, Japan
\end{abstract}

Correspondence to:

Junko Nakamura

Email:

junjun555vl@hotmail.co.jp

Postal address:

The University of Tokyo Hospital, Department of Radiology, 7-3-1 Hongo, Bunkyo-ku, Tokyo 113-8655, Japan

Dates:

Received: 05 Mar. 2014

Accepted: 26 Sept. 2014

Published: 11 Dec. 2014

How to cite this article: Nakamura J, Yoshikawa T, Maeda E, et al. Evaluation of endometrial thickness in postmenopausal women by using 3.0-T MRI. S Afr J Rad. 2014;18(1); Art. \#603, 4 pages. http://dx.doi/ org.10.4102/sajr.v18i1.603

Read online:
Background: The accepted threshold for normal endometrial thickness is $5 \mathrm{~mm}$; lesions with endometrial thickness $<5 \mathrm{~mm}$ are considered benign, whilst those $>5 \mathrm{~mm}$ are considered malignant. However, endometrium $\geq 5 \mathrm{~mm}$ on transvaginal ultrasonography in postmenopausal woman is considered as asymptomatic endometrial thickening. However, recent studies suggest that asymptomatic endometrial thickness of even $8 \mathrm{~mm}-11 \mathrm{~mm}$ in postmenopausal women may be normal.

Objectives: The present study investigated the normal endometrial thickness range in 297 asymptomatic postmenopausal women using 3.0-T magnetic resonance imaging (MRI) T2-weighted sagittal images measured retrospectively by a single radiologist.

Method: The data were classified according to patient age and postmenopausal duration, and the medical records and follow-up MR images were reviewed to assess the clinical outcome.

Results: The mean endometrial thickness was $2.4 \pm 0.1 \mathrm{~mm}$ (range: 0.1-11.6). The endometrium in 21 of 297 subjects was $\geq 5 \mathrm{~mm}$ thick. Follow-up MR images were obtained in 17 of these 21 women, and their endometrial thickness was found to have decreased in all of them. To date, none of the subjects has been diagnosed with endometrial cancer.

Conclusion: Although $5 \mathrm{~mm}$ is considered the conservative threshold of normal endometrial thickness on MRI of postmenopausal women, this figure should not, to avoid excessive false-positive diagnoses, be assumed as an indication of malignancy.

\section{Introduction}

Endometrial abnormalities pose diagnostic challenges for radiologists and gynaecologists. The endometrial appearance is influenced by several factors, such as age, menstrual status, pregnancy and hormonal therapy. Amongst these, menstrual status is potentially the most influential factor affecting endometrial thickness.

Although the accepted normal value for endometrial thickness is $<5 \mathrm{~mm},{ }^{1,2}$ endometrium $\geq 5 \mathrm{~mm}$ on transvaginal ultrasonography (TVUS) imaging in a postmenopausal woman is considered asymptomatic endometrial thickening. ${ }^{3,4,5}$ Current literature concerning TVUS imaging suggests that asymptomatic endometrial thickness of $8 \mathrm{~mm}-11 \mathrm{~mm}$ in a postmenopausal woman may be normal. $6,7,8,9,10$

TVUS may be ideal for reliable and cost-effective evaluation of the female reproductive tract and can measure several parameters including endometrial thickness, endometrial pattern and the endometrial and subendometrial perfusion. ${ }^{11}$ By using three-dimensional ultrasonography (3D US), any plane through an organ can be obtained, and a volume image can be recorded and further analysed in several ways, including navigation, multiplanar display, surface rendering or volume calculation. ${ }^{11,12,13}$ There remains no doubt that TVUS and 3D US are feasible, cost-effective and reliable modalities.

Magnetic resonance imaging (MRI) findings often correlate with US findings. Although MRI is an objective method with higher reproducibility than US, it is not first choice for asymptomatic or general patient screening, mainly because of its cost and scanning time. Therefore, screening pelvic MRI is confined to expensive private programmes, and data detailing the endometrial thickness in normal postmenopausal woman are inadequate. Furthermore, there have not been any studies assessing endometrial thickness on MRI in a sufficiently large study population. The present study investigated endometrial thickness in postmenopausal women by using MRI and correlating the findings to their menstrual activity and age.

Copyright: @ 2014. The Authors. Licensee: AOSIS OpenJournals. This work is licensed under the Creative Commons Attribution License. 


\section{Research method and design Study design}

The present investigation evaluated and compared endometrial thickness in postmenopausal women by using a 3.0-T MRI system. The study was approved by our institutional review board, and written informed consent was obtained from all subjects.

\section{Subject selection}

The study population comprised 679 consecutive women aged 27 to 83 years, who underwent a health-screening programme including pelvic MRI at our institution from April 2007 to February 2008. Each patient completed a medical questionnaire on menstruation, medication use and medical history.

The following were the exclusion criteria: (1) premenopausal status (174 women), (2) unclear menstrual history (72 women), (3) history of hormonal therapy or breast cancer (16 women), (4) history of severe gynaecological disease (7 women), (5) myomatous uterus or massive endometriosis with diffuse deviation or endometrial deviation (31 women) (Figure 1), and (6) hysterectomy (82 women). The remaining 297 postmenopausal women were enrolled in the study and the data classified by patient age and menstrual activity.

\section{Magnetic resonance imaging}

All of the subjects underwent pelvic MRI as part of a healthscreening programme with a 3.0-T MRI system (Signa Excite, GE Healthcare UK, Buckinghamshire, England). Fast spinecho (FSE) sagittal T2-weighted imaging was performed (repetition time: $8000 \mathrm{~ms}$; effective echo time $91.5 \mathrm{~ms}$; field of view $28 \mathrm{~cm}$ ). The acquisition matrix for the FSE images was $384 \times 320$ with a $6 \mathrm{~mm}$ section thickness and a $0.547 \mathrm{~mm}$ intersection gap.

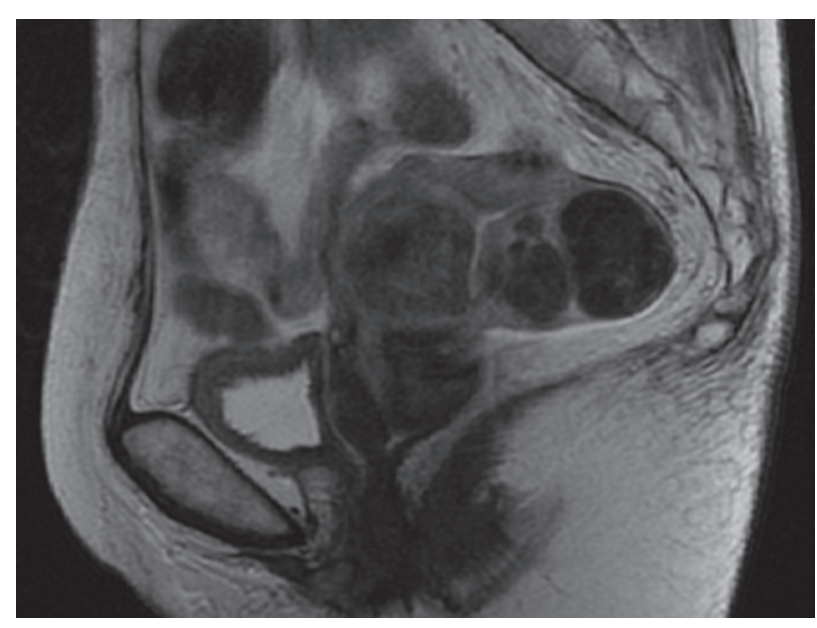

FIGURE 1: Myomatous uterus with diffuse deviation or endometrial deviation.

\section{Magnetic resonance image analysis}

A single radiologist retrospectively measured the endometrial thickness on sagittal T2-weighted images at the thickest site between the two basal layers on the anterior and posterior uterine walls (Figure 2).

\section{Follow-up evaluation}

The medical records were reviewed to assess clinical outcomes. In subjects with an endometrium $\geq 5 \mathrm{~mm}$, the endometrial thickness was also measured on any available follow-up MR images.

\section{Results}

Endometrial thickness of the 297 postmenopausal women (mean age 63 years; range 50-83) was $2.4 \pm 0.1 \mathrm{~mm}$ (mean \pm standard deviation) and ranged between 0.1 and $11.6 \mathrm{~mm}$ (Figure 3). Their endometrial thickness was poorly correlated with patient age $(r=0.026, p=0.652)$ (Figure 3) and postmenopausal duration $(r=0.031, p=0.583$ (Figure 4).

The endometrium was $\geq 5 \mathrm{~mm}$ in 21 of $297(7.1 \%)$ postmenopausal women. Three $(1.0 \%)$ of the 21 women had an endometrium $>10 \mathrm{~mm}$. Two of these women were referred to the gynaecology department following MRI, and one was diagnosed with endometrial hyperplasia, while no malignancy was detected in the second woman (class 1). Follow-up gynaecological examination could not be performed in the remaining case. Follow-up MRI was performed in 17 of 21 women with endometrial thickness $\geq 5 \mathrm{~mm}$ and showed a decreased endometrial thickness in all of them. None of the subjects was diagnosed with endometrial cancer on follow-up examination.

\section{Discussion}

The endometrial thickness was successfully measured in 297 postmenopausal women using 3.0-T MRI. US is

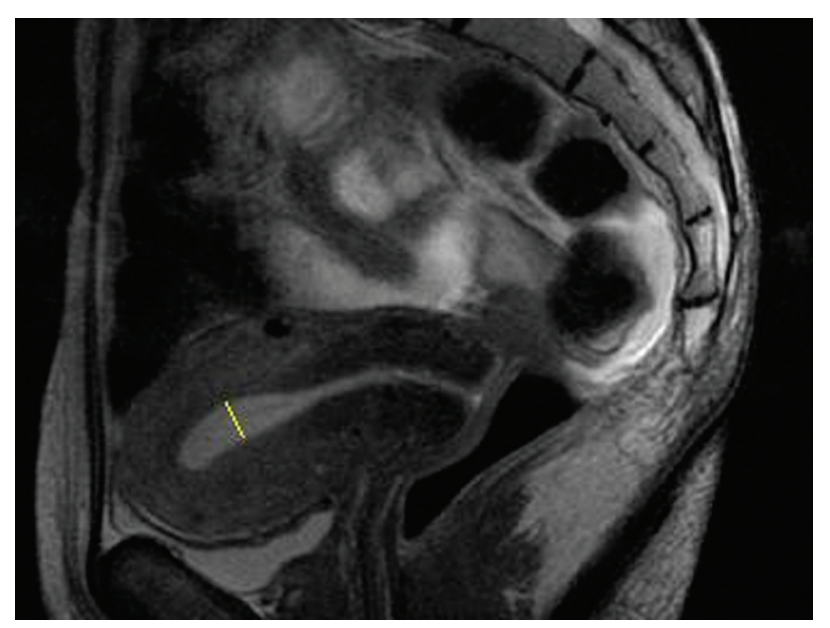

FIGURE 2: Sagittal FSE T2-weighted magnetic resonance (MR) image. The endometrium is well-defined, and a caliper is placed to measure the endometrial thickness. 


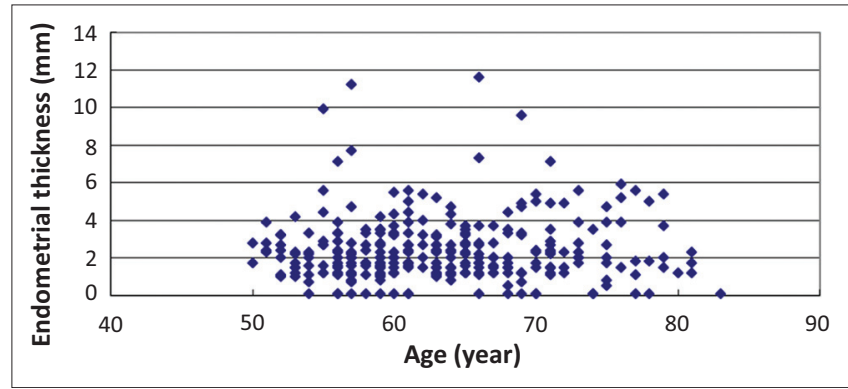

FIGURE 3: Endometrial thickness of 297 postmenopausal women.

commonly used for gynaecological examination because of its convenience and non-invasiveness; however, it has drawbacks. Because US examination depends on operator skill, examinations must be performed by experienced staff with adequate training and skills. Therefore, accurate measurement of endometrial thickness can be difficult if US image quality is suboptimal. Furthermore, US is a poorly reproducible modality, and retrospective evaluation is difficult. In comparison, MRI is highly reproducible and can be re-evaluated at any time. In the present study, MRI was not directly compared with TVUS. Further studies are required to determine whether a single $\mathrm{T} 2$ sagittal sequence is equivalent to TVUS for assessing endometrial thickness.

The present analysis examined whether an endometrial thickness $\geq 5 \mathrm{~mm}$ in postmenopausal women is abnormal in a large sample population. Our findings support previous US studies stating that asymptomatic endometrial thickness of $8 \mathrm{~mm}-11 \mathrm{~mm}$ is most probably normal. ${ }^{6,7,8,9,10}$ In addition, the incidence of endometrial thickening $(\geq 4.5 \mathrm{~mm})$ in postmenopausal women ranges from $3 \%$ to $17 \%, 3,4,5$ while the incidence of endometrial cancer in an unselected postmenopausal population is reportedly 1.3 to $1.7 / 1000$ women. ${ }^{14,15,16}$ Some studies assert that there is no evidence supporting routine screening for asymptomatic endometrial thickening, ${ }^{17,18,19,20}$ and it remains debatable whether an endometrium $\geq 5 \mathrm{~mm}$ should always be considered abnormal.

In the present study, particular attention was focused on the 21 of 297 (7.1\%) postmenopausal women with an endometrium $\geq 5 \mathrm{~mm}$. No cases of malignancy were diagnosed, and only one case $(0.3 \%)$ of hyperplasia was detected. In follow-up MRI of 17 of the 21 subjects, the endometrium was thinner in all 17 cases; to date, none of the subjects has been diagnosed with endometrial cancer. The incidence of postmenopausal women with endometrium $\geq 5 \mathrm{~mm}$ in the present study closely coincided with previous studies.

Similarly to previous studies, our results suggest that there is no evidence supporting routine screening for asymptomatic endometrial thickening, ${ }^{17,18,19,20,21}$ and instead suggest the possibility of a risk of over-diagnosis in postmenopausal women with an endometrium $\geq 5 \mathrm{~mm}$ identified as abnormal without considering other risk factors. In 2010, Goldstein ${ }^{22}$ recommended that postmenopausal asymptomatic endometrial thickening should be evaluated on a case-by-case basis. Even in an elderly patient with

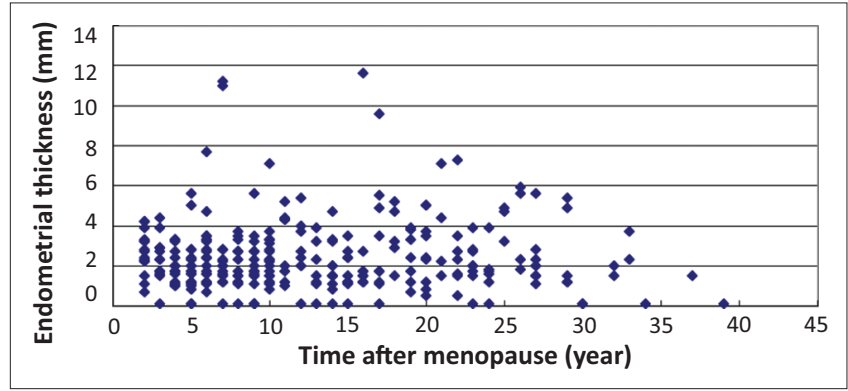

FIGURE 4: Relationship between endometrial thickness and time after menopause in 297 postmenopausal women.

endometrium $\geq 5 \mathrm{~mm}$ and a long postmenopausal period, it is inappropriate to consider the condition abnormal if she is asymptomatic.

The correlation between endometrial thickness, age and postmenopausal duration was also assessed. The results showed that endometrial thickness correlated poorly with postmenopausal duration and patient age. Further studies are required to determine the MRI cut-off to accurately exclude neoplasia. Future studies performing limited MRI examinations prior to endometrial biopsy in patients with endometrial hyperplasia or suspected of having endometrial carcinoma are planned.

\section{Limitations of the study}

The present study has several limitations. The intra-observer error is unknown because all measurements were performed visually by one radiologist. Furthermore, the study does not compare MR and US images in the same subject. Some studies report consistent endometrial thickness on MRI and US compared with histologic measurement in hysterectomy specimens, ${ }^{23,24,25}$ whilst others report a slight but consistent difference between the two modalities. ${ }^{26}$ The third limitation is that endometrial thickness could not be measured correctly on sagittal T2-weighted images owing to postmenopausal haemorrhage; in such cases, a follow-up MRI may be desirable.

In addition to these technical limitations, the costeffectiveness of MRI is also a concern. MRI is an impractical screening tool to evaluate endometrial thickness because it is more costly than TVUS or 3D US. The cost to diagnose an instance of discrepancy was reportedly estimated at $\$ 7200$, and routine $\mathrm{CT}, \mathrm{MRI}$ and tumour markers are not necessary in all patients. ${ }^{27}$ Therefore, it is clear that US is more suitable for screening of endometrial thickness, and MRI should not be used routinely. However, the present results can assist clinicians to correctly interpret MR images performed following an initial screening test.

\section{Conclusion}

Endometrial thickness in postmenopausal women was measured using 3.0-T MRI. The mean thickness was $2.4 \mathrm{~mm}$, and $5 \mathrm{~mm}$ thick in $7 \%$ of patients, but none developed endometrial cancer. The commonly used criterion of $\geq 5 \mathrm{~mm}$ endometrial thickness as a possible sign of malignancy may 
result in an excessive number of false-positives; therefore, a new standard for postmenopausal endometrial thickness should be established.

\section{Acknowledgements}

We thank Dr J. Maharajh and Dr A. Mitha for their help in compiling the images.

\section{Competing interests}

The authors declare that they have no financial or personal relationship(s) that may have inappropriately influenced them in writing this article.

\section{Authors' contributions}

Guarantors of integrity of entire study, J.N. (The University of Tokyo), T.Y. (The University of Tokyo Hospital), K.O. (The University of Tokyo); study concept/study design or data acquisition or data analysis/interpretation, J.N., T.Y., E.M. (The University of Tokyo Hospital), H.A. (The University of Tokyo), N.H. (The University of Tokyo Hospital), K.O. Manuscript drafting or manuscript intellectual content, all authors; manuscript final version approval, all authors; literature research, J.N., T.Y., E.M., H.A., N.H. and K.O.; statistical analysis, H.O. (The University of Tokyo Hospital); and manuscript editing, J.N., T.Y., E.M., H.A., N.H., K.O.

\section{References}

1. Karlsson B, Granberg S, Wikland M, Ryd W, Norström A. Endovaginal scanning of the endometrium compared to cytology and histology in women with postmenopausal bleeding. Gynecol Oncol. 1993;50(2):173-178. http://dx.doi. org/10.1006/gyno.1993.1188

2. Gordstein SR, Nachtigall M, Snyder JR, Nachtigal L. Endometrial assessment by vaginal ultrasonography before endometrial sampling in patients with postmenopausal bleeding. Am J Obset Gynecol. 1990;163(1):119-123. http:// dx.doi.org/10.1016/S0002-9378(11)90683-8

3. Gambacciani M, Monteleone P, Ciaponi M, Sacco A, Ganazzani AR. Clinical usefulness of endometrial screening by ultrasound in asymptomatic postmenopausal women. Maturitas 2004;48(4):4221-4224. http://dx.doi org/10.1016/j.maturitas.2003.10.006

4. Koss L, Schreiber K, Oberlander S, Mamdouh M, Herbert, S. Screening of asymptomatic women for endometrial cancer. CA Cancer J Clin. 1981:31(5):300317. http://dx.doi.org/10.3322/canjclin.31.5.300

5. Vuento $\mathrm{MH}$, Pirhonen JP, Mäkinen JI, et al. Screening for endometrial cance in asymptomatic postmenopausal women with conventional and colour in asymptomatic postmenopausal women with conventional and colour Doppler sonography. Br J Obstet Gynaecol
org/10.1111/j.1471-0528.1999.tb08079.x

6. Smith-Bindman R, Weiss E, Feldstein V. How thick is too thick? When endometrial thickness should prompt biopsy in postmenopausal women without vaginal bleeding. Ultrasound Obset Gynecol. 2004;24(5):558-565. http://dx.doi. org/10.1002/uog.1704
7. Levine D, Gosink BB, Johnson LA. Change in endometrial thickness in postmenopausal women undergoing hormone replacement therapy. Radiology 1995;197(3):603-608. http://dx.doi.org/10.1148/radiology.197.3.7480726

8. Shipley CF III, Simmons CL, Nelson GH. Comparison of transvaginal sonography with endometrial biopsy in asymptomatic postmenopausal women. J Ultrasound Med. 1994;13(2):99-104.

9. Lin $\mathrm{MC}$, Gosink BB, Wolf $\mathrm{Sl}$, et al. Endometrial thickness after menopause Effect of hormone replacement. Radiology. 1991;180(2):427-432. http://dx.doi. org/10.1148/radiology.180.2.1829843

10. Aleem F, Predanic M, Calame R, Moukhtar M, Pennisi J. Transvaginal color and pulsed Doppler sonography of the endometrium: A possible role in reducing the number of dilatation and curettage procedures. J Ultrasound Med. 1995; 14(2):139-145

11. Alcázar JL. Three-dimensional ultrasound assessment of endometrial receptivity A review. Reproductive Biology and Endocrinology. 2006;4:56. http://dx.doi. org/10.1186/1477-7827-4-56

12. Raine-Fenning N, Campbell B, Collier J, Brincat M, Johnson I. The reproducibility of endometrial volume acquisition and measurement with the VOCAL-imaging program. Ultrasound Obstet Gynecol. 2002;19(1):69-75. http://dx.doi. org/10.1046/j.0960-7692.2001.00608.x

13. Alcázar JL, Mercé LT, Manero MG, Bau S, López-García G. Endometrial volume and vascularity measurements by transvaginal 3-dimensional ultrasonography and power Doppler angiography in stimulated and tumoral endometria: An interobserver reproducibility study. J Ultrasound Med. 2005; 24(8):1091-1098.

14. Archer DF, McIntyre-Seltman K, Wilborn WW Jr, et al. Endometrial morphology in asymptomatic postmenopausal women. Am J Obstet Gynecol. 1991;165(2):317320. http://dx.doi.org/10.1016/0002-9378(91)90084-5

15. Gull B, Karlsson B, Milsson I, Wikland M, Granberg S. Transvaginal sonography of the endometrium in a representative sample of postmenopausal women Ultrasound Obstet Gynecol. 1996;7(5):322-327. http://dx.doi.org/10.1046/ j.1469-0705.1996.07050322.x

16. Koss LG, Schreiber K, Oberlander SG, Moussouris HF, Lesser M. Detection of endometrial carcinoma and hyperplasia in asymptomatic women. Obstet Gynecol. 1984;64(1):1-11.

17. American Cancer Society. Cancer Facts \& Figures 2009. Atlanta, GA: American Cancer Society; 2009.

18. Canadian Cancer Society/National Cancer Institute of Canada. Canadian Cancer Statistics 2008. Toronto: Canadian Cancer Society; 2008.

19. Goldstein RB, Bree RL, Benson $C B$, et al. Evaluation of the woman with postmenopausal bleeding: Society of Radiologists in Ultrasound - sponsored consensus conference statement. J Ultrasound Med. 2001;20(1):1025-1036.

20. American College of Obstetricians and Gynecologists. ACOG Committee Opinion No. 426: The role of transvaginal ultrasonography in the evaluation of postmenopausal bleeding. Obstet Gynecol. 2009;113(2):462-464. http://dx.doi. org/10.1097/AOG.0b013e31819930cc

21. Wolfman W, Leyland N, Heywood M, et al. Asymptomatic endometrial thickening. J Obstet Gynaecol Can. 2010;32(10):990-999.

22. Goldstein SR. Modern evaluation of the endometrium. Obstet Gynecol 2010;116(1):168-176. http://dx.doi.org/10.1097/AOG.0b013e3181dfd557

23. Exacoustos C, Zupi E, Cangi B, Chiaretti M, Arduini D, Romanini C. Endometria evaluation in postmenopausal breast cancer patients receiving tamoxifen: An ultrasound, color flow Doppler, hysteroscopic and histological study. Ultrasound Obstet Gynecol. 1995;6(6):435-442. http://dx.doi.org/10.1046/j.14690705.1995.06060435.x

24. Bertelli G, Venturini M, Del Mastro L, et al. Tamoxifen and the endometrium Findings of pelvic ultrasound examination and endometrial biopsy in asymptomatic breast cancer patients. Breast Cancer Res Treat. 1998;47(1):41-46. http://dx.doi. org/10.1023/A:1005820115535

25. Cummings SR, Eckert S, Krueger KA, et al. The effect of raloxifene on risk of breast cancer in postmenopausal women: Results from the MORE randomized trial. Multiple outcomes of raloxifene evaluation. JAMA. 1999;281(23):2189-2197. http://dx.doi.org/10.1001/jama.281.23.2189

26. Mitchell DG, Schonholz L, Hilpert PL, Pennell RG, Blum L, Rifkin MD. Zones of the uterus: Discrepancy between US and MR images. Radiology. 1990;174(3):827-831.

27. Renaud MC, Le T, Le T, et al. Epidemiology and investigations for suspected endometrial cancer. J Obser Gynaecol Can. 2013;35(4):380-383. http://dx.doi. org/10.1148/radiology.174.3.2406787 